\title{
Conjoint Analysis Reveals Consumers Prefer Long, Thin Asparagus Spears
}

\author{
Bridget K. Behe ${ }^{1,2}$ \\ Department of Horticulture, Michigan State University, East Lansing, \\ MI 48824-1325
}

\section{Additional index words. consumer, marketing, survey, vegetable}

\begin{abstract}
Michigan fresh asparagus marketers were interested in profiling asparagus consumers in the Northeast and Midwest with regard to preferences, purchases, preparation, and consumption. A computer-assisted survey was conducted with a total of 1126 respondents representative of the population on average in 12 selected states in the Northeast and Midwest. Even though the U.S. Department of Agriculture recommends adults consume three servings of vegetables daily, on average over the 2 weeks before taking the survey, $62 \%$ did not. Only $39 \%$ of the persons in the sample ate fresh asparagus in the 4 weeks preceding the survey. Twenty-five percent ate it steamed on the stovetop. The conjoint analysis accounted for $63 \%$ of the variance in asparagus preference with attribute relative importance decreasing from price $(42.0 \%)$, to brand $\mathbf{2 9 . 9 \% ) , ~ t o ~ s p e a r ~ d i a m e t e r ~ ( 2 3 . 5 \% ) , ~ t o ~ s p e a r ~ s e g m e n t ~ ( 4 . 6 \% ) . ~ L i g h t ~ u s e r s ~ c o n s u m e d ~ f r e s h ~}$ asparagus at least once in the 4 weeks before the survey, during the peak fresh asparagus season. The potential to increase consumption in this large group $(28 \%$ of the sample but $\mathbf{7 1 \%}$ of asparagus consumers) is tremendous. They placed high relative importance on price per pound and will likely be the more price-sensitive group. If their consumption can be increased by one more asparagus consumption event per month, it could increase asparagus demand by $14 \%$. Results show there is good market potential for a prepackaged fresh asparagus product in the Northeast and Midwest.
\end{abstract}

Among vegetables, asparagus (Asparagus officinalis L.) is the leading supplier of folic acid for human nutrition, which is necessary for blood cell formation, growth, and prevention of liver disease. Folacin plays a significant role in the prevention of neural tube defects, such as spina bifida, that cause paralysis and death in infants. Asparagus is low in calories, contains no fat or cholesterol, is very low in sodium, and is a good source of potassium, fiber, thiamin, B6, and one of the richest sources of rutin, a chemical that strengthens capillary walls (Michigan Asparagus Council, 2005), making asparagus a wise choice for health-conscious consumers.

The United States is the third leading world producer of asparagus behind China and Peru. In 2003, domestic producers grew $57 \mathrm{~m} \mathrm{~kg}$. and imported $84 \mathrm{~m} \mathrm{~kg}$. of asparagus, exporting only $14 \mathrm{~m} \mathrm{~kg}$. California, Washington, and Michigan were the top three producing US states for fresh market asparagus. The fresh market crop was valued at $\$ 137$ million in 2002. Per capita consumption averaged $0.43 \mathrm{~kg}$. from 2000 to 2002, up $60 \%$ from a decade ago and three times greater than 20 years ago (USDA, 2005).

The US Department of Agriculture (USDA) recommends Americans consume

Received for publication 7 Mar. 2006. Accepted for publication 27 Apr. 2006. This research was generously funded through the Michigan State University Center for Product Agriculture with Project GREEEN funds and with USDA and Michigan Asparagus Advisory Board funds. ${ }^{1}$ Professor.

${ }^{2}$ To whom reprint requests should be addressed; e-mail behe@msu.edu. three servings of vegetables daily, but most consumed only half that recommended amount (Reed, Frazao, and Itskowitz, 2004). These researchers showed that $57 \%$ of vegetables were least expensive in their raw form. Of the 154 forms of fruits and vegetables investigated, half cost $\$ 0.25$ per serving or less. Among the 30 vegetables studied, potatoes were the most widely consumed vegetable (4 billion $\mathrm{lb}$.), followed by tomatoes ( 1.6 billion $\mathrm{lb}$.), onions ( 1.3 billion lb.), and corn (1.1 billion lb.). Asparagus ranked 18th in consumption of the vegetables studied, with Americans eating 127.5 million lb. in 1999, or 316 million servings.

With the rising popularity of fresh products ready for consumption, the Michigan Asparagus Advisory Board was interested in developing a fresh asparagus product ready for consumption in a microwaveable package. The cleaned and packaged asparagus would be ready for cooking in a microwave, which would reduce consumer's preparation time. However, no information has been published on asparagus consumption and consumer preferences. This study was developed to investigate consumer purchases, preparation, consumption, and preferences of fresh asparagus in the Midwest and northeastern United States, markets most proximate to Michigan asparagus production.

\section{Materials and Methods}

A survey was developed with questions to determine vegetable consumption behavior and, in particular, asparagus purchasing, preparation, and consumption. The survey protocol and instrument were approved by the
University Committee on Research Involving Human Subjects before implementation.

In addition to purchasing, preparation, and consumption questions, a conjoint study was constructed to determine the relative importance of four asparagus attributes: spear diameter, length and segment used, price, and brand name. Conjoint analysis allowed researchers to investigate simultaneously a number of product attributes and determine the relative importance of each attribute in the consumer's preference. Others used this method to determine consumer preferences for bell peppers (Frank et al., 2000), geraniums (Behe et al., 1999), outdoor ornamental plants (Townsley-Brascamp et al., 1995), residential landscapes (Behe et al., 2005a), and table-top Christmas trees (Behe et al., 2005b).

An additive model was used in which the preference for each factor was added to form the overall preference for a particular plate of asparagus. For each factor, scientists identified a hierarchical set of levels to investigate. Two spear lengths were identified: short spears measured $7.5 \mathrm{~cm}$ and long spears were $15 \mathrm{~cm}$ long, measured from the spear tip. Spear diameter was either small $(<1 \mathrm{~cm})$ or large $(\geq 1 \mathrm{~cm})$, measured $15 \mathrm{~cm}$ from the tip. Spear segment used was either tips (top 7.5 or $15 \mathrm{~cm}$ ) or tips and cuts (top 7.5-cm segment and subsequent $7.5-\mathrm{cm}$ segment). Price was identified at three price points: $\$ 1.49, \$ 2.25$, and $\$ 2.99 / \mathrm{lb}$. Brand name was the final variable considered. One currently marketed brand name (although not for fresh asparagus) was used with two potential names under consideration by asparagus marketers: Green Giant, Sweet Tips, and Tender Tips. A fourth brand alternative was given as a generic label. The design was a $2 \times 2 \times 3 \times 4$ factorial. Researchers reduced the number of combinations required from 48 to 16 by using a partial factorial design, while maintaining factor orthogonality, which decreased potential participant fatigue. Participants were asked to rate "how much they liked" each plate of asparagus on a 5-point Likert scale $(1=$ like very little, $5=$ like very much) . Conjoint analysis defines the overall consumer preference for a particular product, in this case a plate of asparagus, as the sum of the part-worths, also defined as utilities, for each factor level. Conjoint and other statistical analyses were completed using SPSS 10.0 (SPSS, Inc., Chicago, Ill.).

Fresh asparagus spears were harvested from a Michigan farm $2 \mathrm{~d}$ before photographing and stored in a $4.4{ }^{\circ} \mathrm{C}$ cooler. Spears were washed and sorted by diameter: $<1 \mathrm{~cm}$ was classified as small, $\geq 1 \mathrm{~cm}$ was classified as large. Spears were trimmed with a knife to $15-\mathrm{cm}$ segments from the top of the spear (long) or $7.5 \mathrm{~cm}$ (short). A professional photographer took digital images of asparagus spears on 26 May 2005 (Fig. 1). A visually similar number of spears were placed on a 20 -cm-diameter white plate with a U.S. coin added as a scale reference.

Knowledge Networks was subcontracted to provide a scientific probability sample of 


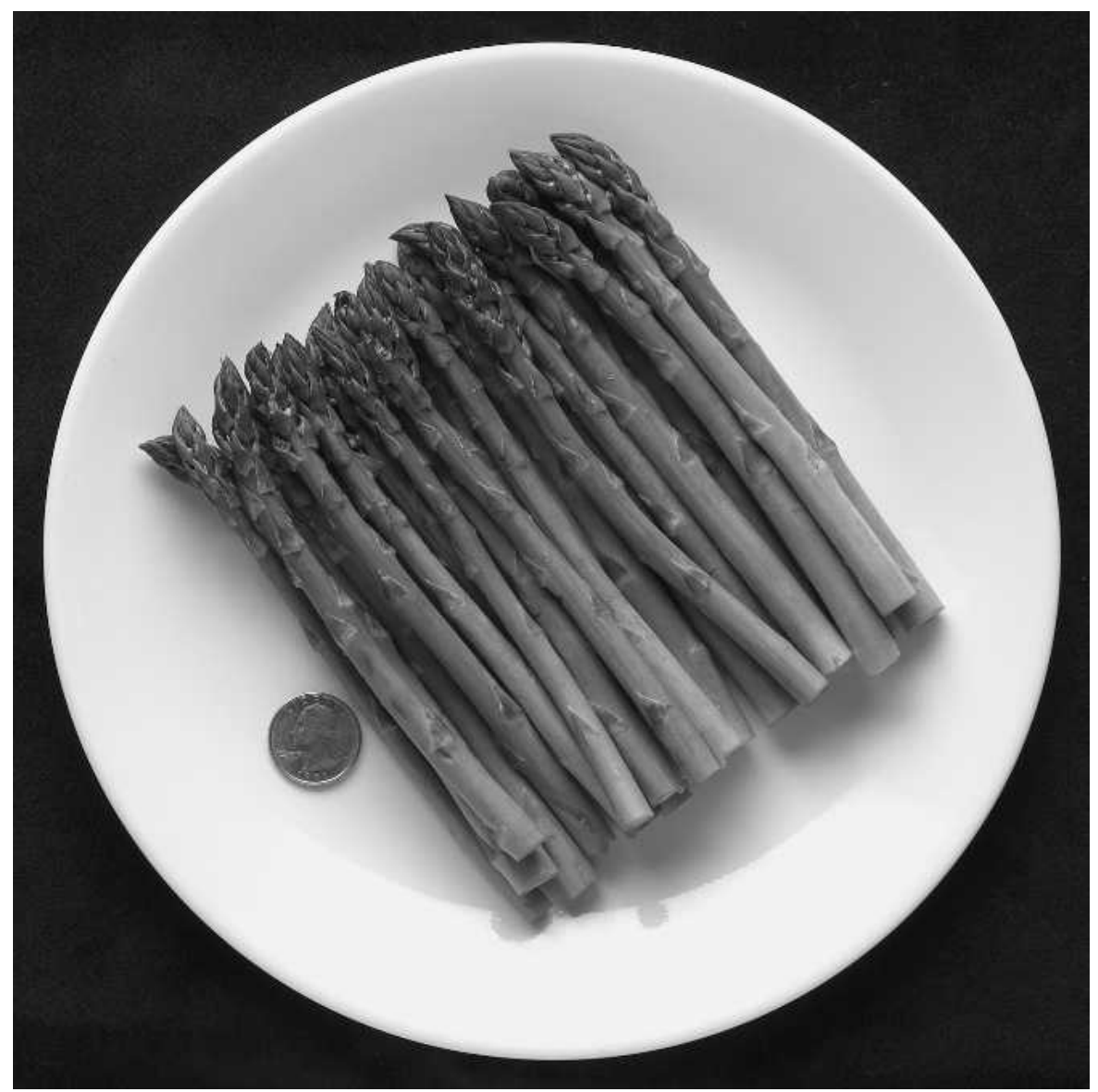

Fig. 1. Most preferred asparagus length, diameter, brand, and price in consumer survey. Photograph by Kurt Stepnitz.

US households. They provided a sample using an online panel based on a random sample of the full U.S. population and, therefore, is representative of the population in the 11 states included in the study. If Internet access was not available to a participant, Knowledge Networks provided a computer and Internet access. They conduct survey research for economic, social, and political research for clients, who include Stanford and Harvard universities, and CBS News.

Given an interest in developing a market proximate to Michigan production, a sample of at least 100 persons was drawn from each of five midwestern states (Michigan, Ohio, Illinois, Indiana, and Wisconsin) and five northeastern states (New York, New Jersey, Pennsylvania, Vermont, and Maine combined, and Massachusetts). Additionally, 100 persons from Washington state (the second largest asparagus domestic producer) were included. Given Washington state's population proximity to fresh asparagus, that market may be more receptive to a fresh, packaged-asparagus product. A sample with a minimum of 100 people would provide a sufficient size to make comparisons in a $2 \times$ 5 cross-tabulation, with an expected value of 10 per cell. Interviews were conducted from 23 June through 12 July 2005, nearing the end of peak asparagus harvest in Michigan.

\section{Results and Discussion}

Responses collected from each state were as follows: Maine, $\mathrm{n}=38$; Vermont, $\mathrm{n}=38$; Massachusetts, $n=45$; New York, $n=116$; New Jersey, $\mathrm{n}=111$; Pennsylvania, $\mathrm{n}=110$; Ohio, $\mathrm{n}=113$; Indiana, $\mathrm{n}=115$; Illinois, $\mathrm{n}=$ 99; Michigan, $\mathrm{n}=110$; Wisconsin, $\mathrm{n}=118$; and Washington, $\mathrm{n}=113$; for a total of 1126 respondents.

\section{Sample demographics}

Participant age ranged from 18 to 90 years, with $27 \%$ of the sample between the ages of 30 and 44 years and $29.2 \%$ of the participants between the ages of 45 and 59 . Mean age was 47.6 years. Eighty-seven percent had completed a high school education or beyond; $28.6 \%$ had completed a bachelor's degree or more. Fifty-eight percent of the participants were married; $23 \%$ were single (never married). Fifty-five percent of the participating households were dual income. Forty-eight percent of the participants were male; $52 \%$ were female. Eighty-two percent were white, $8.3 \%$ were black, $4.7 \%$ were Hispanic, $2.1 \%$ were other ethnic background but non-Hispanic, and 3.3\% reported they were from a multiethnic background. Nineteen percent of the participants were from single-person households, $41 \%$ from two-person households, $18 \%$ from three-per- son households, and 9\% from more than three-person households. Median household income was in the category of $\$ 40,000$ to $\$ 49,999$. Seventy percent of the participants owned their home and nearly $60 \%$ of the participating households had Internet access.

\section{Vegetable consumption}

Even though the USDA recommends adults consume three servings of any type of vegetable on a daily basis, on average over the 2 weeks before taking the survey, $29 \%$ of the participants ate one serving of vegetables daily, $27 \%$ at two servings, and $11.5 \%$ ate three servings. Nearly $6 \%$ ate no servings of vegetables, but $26.5 \%$ ate three or more servings of vegetables on average per day. Where were those servings consumed? Only $5 \%$ said none of the servings were consumed at home. Sixty-five percent said one to three servings were consumed at home, with the remainder consuming many more servings at home.

How were the vegetables eaten? Nearly $80 \%$ said at least one of their vegetable servings was consumed raw, which is defined as fresh, not cooked or processed (except for washing). Sixty-five percent of the respondents reported purchasing bagged salad or greens or lettuce mix. Only $19.8 \%$ said no servings were consumed raw. Many cooked vegetables indoors $(95 \%)$; only $5.6 \%$ said they did not cook any vegetable servings indoors. Only $8 \%$ cooked some vegetable servings outdoors, such as grilled or roasted.

Only $39 \%$ of the persons in the sample ate fresh asparagus in the 4 weeks preceding the survey. Seventeen percent said they ate it once in the month before the survey, $11 \%$ said they ate it two to three times in that month, 5.6\% ate it weekly, and another 5\% ate it two to six times per week. Almost 1\% ate fresh asparagus daily. Most of those asparagus servings $(95 \%)$ were consumed at home. Fewer than $6 \%$ ate it away from home (at a restaurant or another home). Twenty-six percent reported another adult in the home who ate asparagus at least once in the month before the survey. Only $18 \%$ reported someone in the household younger than 18 years eating fresh asparagus at least once in the month before the survey.

Respondents were asked whether they had personally purchased the asparagus; $21 \%$ had. A greater percentage of women (76.5\%) purchased asparagus compared with men $(42.9 \%)$. Of those 234 respondents who did purchase asparagus, $9.4 \%$ bought $\sim 4 \mathrm{oz}$. at each purchase event, $21.8 \%$ purchased 0.5 lb., $13.6 \%$ purchased 12 oz., and $38 \%$ purchased $1 \mathrm{lb}$. Nearly $17 \%$ reported purchasing more than $1 \mathrm{lb}$. at each purchase event.

Many more women $(85 \%)$ than men $(44.2 \%)$ prepared fresh asparagus for consumption. Of the total respondents, 393 persons prepared the asparagus (or 34.9\%). Of those, $64 \%$ washed the asparagus before consuming it. When asked if the person who prepared the asparagus had any difficulty in cleaning the spears, most $(91.6 \%)$ indicated no problems. When asked how easy or 
difficult was the most difficult bunch to clean, $39.1 \%$ said somewhat easy to very easy, $10.5 \%$ said neither easy nor difficult, and $2.8 \%$ said somewhat difficult to very difficult to clean $(48.6 \%$ did not clean asparagus). With more than one response permitted, most $(87.3 \%)$ snapped the bottom off the spear while some $(59.6 \%)$ cut off the spear bottom, and a few $(13.9 \%)$ peeled the bottom of the spear. When asked whether it made a difference if the bottom of the spear was snapped or cut off, $33 \%$ indicated yes, $51 \%$ indicated no, and $16 \%$ didn't know. Snapping versus cutting could be an important and marketable distinction, because Michigan asparagus is harvested by snapping spears in Michigan, eliminating the tough white stem bottom.

Only $6 \%$ of those consuming asparagus ate asparagus after grilling it outdoors, $3.6 \%$ ate it steamed from an electric steamer, $25 \%$ ate it steamed on the stovetop, $4 \%$ ate it roasted indoors, $7 \%$ ate it steamed from a microwave, $6 \%$ ate it heated in a skillet (not steamed), 5.2\% ate it stir fried, and 2.8\% ate it raw. A microwaveable pouch or tray, suitable for steaming fresh asparagus, readily fits the preparation behavior for at least onefourth of consumers.

Only those participants who had eaten some asparagus in the 4 weeks before the survey participated in the conjoint portion of the study $(\mathrm{n}=336)$ and were shown the 16 photographs of asparagus spears. The conjoint design was significant and accounted for $63 \%$ of the variance in preference. The relative importance of the factors decreased from price $(42.0 \%)$, to brand $(29.9 \%)$, to diameter $(23.5 \%)$ to length $(4.6 \%)$ (Table 1). The most preferred combination was a small-diameter, long spear priced at $\$ 1.49 / 1$ b. with the brand name Green Giant (mean, 3.72) (Fig. 1). The least preferred combination was the large diameter with tips and stems priced at $\$ 2.25 / \mathrm{lb}$. with the brand name Sweet Tips, with a mean rating of 2.27 . Consumers preferred smaller diameter spears over larger diameter spears, and long spears over tips and cuts or tips only. They preferred lower price per pound over high price per pound and preferred the brands Green Giant

Table 1. Relative importance and utility for four factors in a conjoint study of consumer preferences for asparagus spears among 336 participants who had eaten asparagus in the 4 weeks before the survey.

\begin{tabular}{|c|c|c|c|}
\hline Factor & Level & $\begin{array}{c}\text { Relative } \\
\text { importance, \% }\end{array}$ & Utility \\
\hline \multirow[t]{2}{*}{ Diameter } & Small & 23.5 & 0.1507 \\
\hline & Large & & -0.1507 \\
\hline \multirow[t]{4}{*}{ Brand } & Tender Tips & 29.9 & 0.1474 \\
\hline & Green Giant & & 0.1354 \\
\hline & Generic & & -0.2362 \\
\hline & Sweet Tips & & -0.0466 \\
\hline \multirow[t]{3}{*}{ Length } & Spear tips & 4.6 & 0.0294 \\
\hline & Tips and cuts & & 0.0589 \\
\hline & Long spears & & 0.0883 \\
\hline \multirow[t]{3}{*}{ Price per $\mathrm{lb}$} & $\$ 1.49$ & 42.0 & -0.2688 \\
\hline & $\$ 2.25$ & & -0.5376 \\
\hline & $\$ 2.99$ & & -0.8064 \\
\hline
\end{tabular}

$R^{2}=0.63, P=0.0045$. and Tender Tips similarly over generic or the brand Sweet Tips.

Women placed a greater relative importance on length and a numerically greater importance on price (Table 2). Men placed a greater relative importance on spear diameter, brand, and price. Participants age 49 years (median age for the sample) and younger placed a greater relative importance on brand and price compared with participants 50 years old and older (Table 3 ).

The sample of asparagus consumers was divided into three groups based on consumption frequency: nonusers, light, and heavy. Heavy consumers had eaten asparagus daily to weekly in the 4 weeks before the survey. Light users ate asparagus at least once in the 4 weeks before the survey, but not as frequent as weekly. Using these definitions, there were 682 nonconsumers (61\%), 312 light users $(28 \%)$, and 128 heavy users $(11 \%)$. There was no significant difference in gender $\left(\chi^{2}=\right.$ $0.17, P=0.897)$, age distribution $\left(\chi^{2}=5.908\right.$, $P=0.739)$, or income distribution $\left(\chi^{2}=\right.$ $13.853, P=0.110)$ of light and heavy users. Heavy users made one more shopping trip to a supermarket or farm market (either on-site or community) for groceries (mean, 4.8 times) in the 2 weeks before the survey compared with light users (mean, 3.8 times; $P=0.027$ ).

There were no significant differences between light and heavy users when asked about cleaning, or snapping, cutting, or peeling the bottom of the spear. Light users placed a greater relative importance on price than heavy users (Table 4). Heavy users had a higher relative importance for spear diameter and length, and slightly greater relative importance on brand. There were only two attitudinal differences between light and heavy users (Table 5). More light users agreed or strongly agreed that they prefer thin asparagus spears over thicker ones, and slightly more light users agreed or strongly

Table 2. Relative importance and utility by gender for four factors in a conjoint study of consumer preferences for asparagus spears among 336 participants who had eaten asparagus in the 4 weeks before the survey.

\begin{tabular}{lcc}
\hline Factor & Women, ${ }^{\mathrm{z}} \mathrm{n}=175$ & Men, ${ }^{\mathrm{y}} \mathrm{n}=161$ \\
\hline Diameter & 22.1 & 24.6 \\
Brand & 28.0 & 31.7 \\
Length & 7.9 & 2.0 \\
Price per lb. & 42.0 & 41.7 \\
\hline
\end{tabular}

${ }^{\mathrm{z}} R^{2}=0.60, P=0.0075$

${ }^{\mathrm{y}} R^{2}=0.66, P=0.0028$.

Table 3. Relative importance and utility by age group for four factors in a conjoint study of consumer preferences for asparagus spears among 336 participants who had eaten asparagus in the 4 weeks before the survey.

\begin{tabular}{lcc}
\hline & \multicolumn{2}{c}{ Age, $\mathrm{y}$} \\
\cline { 2 - 3 } Factor & $\leq 49,{ }^{\mathrm{z}} \mathrm{n}=168$ & $\geq 50,{ }^{\mathrm{y}} \mathrm{n}=168$ \\
\hline Diameter & 16.6 & 28.1 \\
Brand & 32.5 & 24.1 \\
Length & 5.6 & 15.5 \\
Price per pound & 45.3 & 32.3 \\
\hline
\end{tabular}

${ }^{\mathrm{z}} R^{2}=0.63, P=0.0046$.

${ }^{\mathrm{y}} R^{2}=0.66, P=0.0027$.
Table 4. Relative importance and utility by consumption level for four factors in a conjoint study of consumer preferences for asparagus spears among 336 participants who had eaten asparagus in the 4 weeks before the survey.

\begin{tabular}{lcc}
\hline Factor & $\begin{array}{c}\text { Heavy } \\
\text { consumers, } \\
\mathrm{n}=90\end{array}$ & $\begin{array}{c}\text { Light } \\
\text { consumers, } \\
\mathrm{n}=246\end{array}$ \\
\hline Diameter & 27.1 & 12.6 \\
Brand & 31.0 & 28.7 \\
Length & 5.6 & 1.6 \\
Price per pound & 36.4 & 57.0 \\
\hline
\end{tabular}

${ }^{\mathrm{z}} R^{2}=0.63, P=0.0043$.

${ }^{\mathrm{y}} R^{2}=0.65, P=0.0032$.

agreed that some asparagus spears are tougher than others.

Two groups were created based on the response to the statement, "I would buy a package of clean asparagus, cut and ready to steam in a microwaveable pouch or tray." Those who responded 1 through 3 on the 5 point Likert scale were labeled "not likely to buy" and those who responded with a 4 or 5 were labeled "likely to buy." Comparing these two groups demographically, several differences emerged. Those "likely to buy" were from smaller household sizes than those "not likely to buy." Both groups had a similar percentage of home owners and housing type, men and women, education, were married and from a dual-income household, have children younger than 2 years old in the household, and were of a similar age. Of those "likely to buy," 74\% had Internet access compared with $61 \%$ of those "not likely to buy" $\left(\chi^{2}=6.831, P=0.006\right)$. A higher percentage of those "likely to buy" had children ages 13 to 17 years in the household compared with those "not likely to buy" $\left(\chi^{2}=7.229, P=0.065\right)$.

\section{Conclusions and Recommendations}

More than half of the nonconsumers from the Northeast and Midwest indicated a positive response to purchasing prepackaged asparagus. However, it may be a considerable challenge to get a nonconsumer to make a first purchase compared with having a current consumer make a subsequent purchase. Some nonconsumers may perceive a prepackaged product as being so convenient that they would make a first purchase of asparagus.

Taking the consumption frequency data and applying it to a hypothetical market of 100,000 people older than 18 years, an estimate of market demand can be derived. There is substantially greater market potential among light consumers than heavy consumers for a packaged asparagus product. In a market of 100,000 residents, nearly 40,000 people will eat asparagus each month. If a typical serving is $0.5 \mathrm{lb}$. unprocessed asparagus, the combined consumption of light consumers who ate it less than weekly but at least once per month is $\sim 40,000 \mathrm{lb}$. However, heavy consumers who eat asparagus at least weekly but account for only $29 \%$ of the asparagus consumers likely eat $100,000 \mathrm{lb} . /$ month. A market of 100,000 
Table 5. Responses from heavy (weekly or more frequent) and light (less than weekly but at least monthly) asparagus consumers to attitudinal questions regarding asparagus.

\begin{tabular}{|c|c|c|c|c|c|c|c|}
\hline & \multicolumn{3}{|c|}{ Heavy, $\mathrm{n}=124$} & \multicolumn{3}{|c|}{ Light, $\mathrm{n}=312$} & \multirow[b]{2}{*}{$P$ value } \\
\hline & $\overline{\mathrm{SD} / \mathrm{D}}$ & $\mathrm{N}$ & $\overline{\mathrm{A} / \mathrm{SA}}$ & $\overline{\mathrm{SD} / \mathrm{D}}$ & $\mathrm{N}$ & $\overline{\mathrm{A} / \mathrm{SA}}$ & \\
\hline $\begin{array}{l}\text { Locally grown produce is fresher than produce } \\
\text { imported from other countries }\end{array}$ & 9.7 & 16.9 & 73.4 & 5.8 & 24.0 & 70.2 & 0.127 \\
\hline $\begin{array}{l}\text { Asparagus spears are tough at the bottom, so } \\
\text { I don't eat them }\end{array}$ & & & & & & & \\
\hline $\begin{array}{l}\text { Thick asparagus spears are tougher than thin } \\
\text { asparagus spears }\end{array}$ & 22.4 & 30.4 & 47.2 & 15.4 & 29.5 & 55.1 & 164 \\
\hline Asparagus is difficult to clean & 66.1 & 25.8 & 8.1 & 66.7 & 27.9 & 5.4 & 570 \\
\hline Asparagus is a "special treat" vegetable & 31.2 & 28.0 & 40.8 & 23.2 & 26.4 & 50.5 & 0.128 \\
\hline $\begin{array}{l}\text { I would eat asparagus more often if it were } \\
\text { washed and ready to cook }\end{array}$ & 54.4 & 31.2 & 14.4 & 44.6 & 32.4 & 23.1 & 0.077 \\
\hline rs over thicker spears & 23.8 & 32.5 & 43.7 & 16.1 & 25.1 & 58.8 & $0.014 *$ \\
\hline My fa & 15.0 & 18.1 & 66.9 & 15.8 & 20.3 & 64.0 & 832 \\
\hline Tender, fresh asparagus is difficult to find & 39.2 & 37.6 & 23.2 & 31.1 & 39.7 & 29.2 & 0.221 \\
\hline $\begin{array}{l}\text { I would buy a package of clean asparagus, cut and } \\
\text { ready to steam in a microwaveable pouch or tray }\end{array}$ & 50.8 & 20.2 & 29.0 & 41.0 & 23.1 & 35.6 & 0.176 \\
\hline te great grilled & 16.0 & 46.4 & 37.6 & 17.4 & 54.5 & 28.1 & 0.145 \\
\hline $\begin{array}{l}\text { aragus stems would taste good served } \\
\text { ke carrots, with a dip }\end{array}$ & 31.0 & 29.4 & 39.7 & 31.9 & 32.9 & 35.2 & 0.644 \\
\hline Asparagus is an expensive vegetable & 28.3 & 33.9 & 37.8 & 16.3 & 34.6 & 49.0 & $0.011 *$ \\
\hline $\begin{array}{l}\text { Asparagus spears are good when served } \\
\text { as a raw vegetable }\end{array}$ & 38.1 & 33.3 & 28.6 & 38.1 & 30.8 & 31.1 & 0.829 \\
\hline I prefer a microwaveable tray over a pouch & 43.2 & 38.4 & 18.4 & 34.7 & 44.7 & 20.6 & 0.252 \\
\hline $\begin{array}{l}\text { Prepackaged vegetables a } \\
\text { when I want to eat fres }\end{array}$ & 30.7 & 29.1 & 40.2 & 24.7 & 29.8 & 45.5 & 0.398 \\
\hline Some a & 8.0 & 22.4 & 69.6 & 2.6 & 20.2 & 77.2 & $0.026^{*}$ \\
\hline Some asparagus spears are sweeter than others & 10.3 & 30.2 & 59.5 & 6.4 & 33.3 & 60.3 & 0.349 \\
\hline
\end{tabular}

people is likely to demand $140,000 \mathrm{lb}$. of asparagus per month.

Heavy users accounted for $11 \%$ of the sample but $29 \%$ of asparagus consumers and $71 \%$ of total asparagus consumed. They already ate asparagus daily to weekly in the 4 weeks before the study. Although a small percentage of the sample, they consume the majority of asparagus. If they purchase $1 \mathrm{lb}$. of asparagus per week, they consume 4 to 10 times the asparagus that light consumers do. The potential to increase their level of consumption is not as great as the potential to increase consumption by light users. Heavy users did not appear to place as much importance on price per pound of asparagus as the light users.
Light users consumed fresh asparagus at least once in the 4 weeks before the survey, which was during peak fresh asparagus season. The potential to increase consumption in this large group (28\% of the sample but $71 \%$ of asparagus consumers) is tremendous. They placed great importance on price per pound and will likely be the most price-sensitive group of the two. How much would their eating one additional serving of asparagus each month add to total consumption? In a hypothetical market of 100,000 people, light consumers who ate it less than weekly but at least once per month is $\sim 40,000 \mathrm{lb}$. If their consumption can be increased by one more asparagus consumption event per month $(0.5$ lb. unprocessed asparagus per person), it could increase asparagus demand by 20,000 lb. or $14 \%$ in a market of $140,000 \mathrm{lb}$.

Because there were no demographic and few attitudinal differences observed between light and heavy users, a relatively homogeneous marketing plan should be most effective. Long, thin spears can be marketed equally well as thin tips and cuts. The use of the Tender Tips brand should also be effective in the marketing plan.

\section{Literature Cited}

Behe, B., J. Hardy, S. Barton, J. Brooker, T. Fernandez, C. Hall, J. Hicks, R. Hinson, P. Knight, R. McNiel, T. Page, B. Rowe, C. Safley, and R. Schutzki. 2005a. Landscape plant material, size, and design sophistication increase perceived home value. J. Env. Hort. 23:127-133.

Behe, B., R. Nelson, S. Barton, C. Hall, C.D. Safley, and S. Turner. 1999. Consumer preferences for geranium flower color, leaf variegation, and price. HortScience 34:740-742.

Behe, B.K., R.M. Walden, M. Duck, B. Cregg, K. Kelley, and R.D. Lineberger. 2005b. Consumer preferences for and cost of production of tabletop Christmas trees. HortScience 40: 409-412.

Economic Research Service, USDA. 2005. Briefing room: Vegetables and melons: Asparagus. 19 July 2005. http://www.ers.usda.gov/Briefing/Vegetables/.

Frank, C.A., R.G. Nelson, E.H. Simonne, B.K. Behe, and A.H. Simonne. 2001. Consumer preferences for color, price, and vitamin $\mathrm{C}$ content of bell peppers. HortScience 36:795-800.

Michigan Asparagus Council. 2005. July 1005. http://www.asparagus.org/maab/nutrition.html. Accessed 20 June 2006

Reed, J., E. Frazao, and R. Itskowitz. 2004. How much do Americans pay for fruits and vegetables? USDA agriculture information bulletin 790. http://www.ers.usda.gov/publications/ aib790/.

Townsley-Brascamp, W., N.E. Marr, E. Matsuo, and P.D. Relf. 1995. Evaluation and analysis of consumer preferences for outdoor ornamental plants. Acta Hort. 391:199-206.

U.S. Census Bureau. 2006. U.S. Interim projections by age, sex, race, and Hispanic origin. 20 Apr. 2006. http://www.census.gov/ipc/ www/usinterimproj/.

USDA. 2005. Economic research service. Vegetables Briefing. 15 Dec. 2005. http://www.ers. usda.gov/Briefing/Vegetables/. 